\title{
Associations of social and environmental supports with sedentary behavior, light and moderate-to-vigorous physical activity in obese underserved adolescents
}

\author{
Hannah G Lawman ${ }^{1 *}$ and Dawn K Wilson ${ }^{2}$
}

\begin{abstract}
Background: Evidence to support differential health impacts of sedentary behavior (SB), light physical activity (LPA), and moderate-to-vigorous physical activity (MVPA) is building. However, few studies have examined individual, social, and environmental supports across the full range of sedentary and physical activities, including key influences such as self-efficacy, parenting factors, and home and neighborhood resources. This may be particularly important in underserved (low-income, minority), overweight/obese adolescents due to the social and environmental challenges (lack of resources, etc.) associated with increasing MVPA. This study evaluated a range of bioecological factors including individual (self-efficacy), parental (parental support, monitoring, limit-setting, and nurturance), and environmental (perceived home resources for PA and neighborhood support for PA) predictors of SB, LPA and MVPA in overweight/obese adolescents.

Methods: Overweight/obese and predominantly minority adolescents and caregivers ( $n=181)$ completed measures in 2010 in the US including surveys assessing self-efficacy for PA, parenting variables related to PA and home and neighborhood supports for PA. Outcomes included 7-day accelerometer estimates of SB, LPA, and MVPA.

Results: Regression analyses showed parental social support and neighborhood support were significantly associated with LPA. No significant associations were found for SB or MVPA.

Conclusions: Results emphasized the importance of examining a range of sedentary and PA intensities and highlighted the role of parental and neighborhood social supports for LPA. These results have important implications that suggest that health promotion efforts should target social and environmental supports for increasing LPA in youth who are overweight/obese.
\end{abstract}

Keywords: Parent support for physical activity, Neighborhood support for physical activity, Self-efficacy for physical activity, Accelerometer, Minority, Overweight, Childhood obesity

\section{Introduction}

Increasing evidence suggests that social and physical environments are important determinants of obesity and physical activity (PA) in youth $[1,2]$. However, only limited research has investigated social and environmental determinants across the full continuum of sedentary and PA intensities (i.e., sedentary (SB), light (LPA), moderate,

\footnotetext{
* Correspondence: hlawman@temple.edu

${ }^{1}$ Center for Obesity Research and Education, Temple University, 3223 N.

Broad Street suite 175, Philadelphia, PA 19140, USA

Full list of author information is available at the end of the article
}

and vigorous (MVPA)) [3]. This may be particularly important in underserved (low-income, racial/ethnic minority) and overweight/obese youth who display a greater number of cardiometabolic risk factors [4] and face increased barriers for engaging in PA [5].

The current study utilizes the bioecological model [6] to provide a guiding framework for understanding individual, family, and environmental determinants of SB, LPA, and MVPA in youth. Additionally, the EnRG framework adds to the bioecological model by hypothesizing that dualprocesses are important in testing whether environmental 
factors may influence behavior both directly and indirectly [1]. Previous studies have supported perceived and objective environmental factors as moderators of the link between individual cognitive factors and behavior $[7,8]$. Consistent with the bioecological model and the EnRG framework's emphasis on cognitive factors such as perceived behavioral control, one potentially important individual level factor is self-efficacy. Previous reviews [9], meta-analyses [10], and studies with underserved youth [11] have also shown that self-efficacy is a key cognitive factor in understanding youth's MVPA. At the environmental level, key factors in understanding youth MVPA have included home and neighborhood characteristics such availability of resources, safety, and neighborhood social support $[12,13]$. However, this study expands on previous research by hypothesizing that parenting variables including parent support [14], monitoring and limit-setting [15-17], and parental nurturance [18] will be important determinants of SB and PA in youth beyond environmental factors.

The influence of social environmental and parenting factors may also differ as a function of PA intensity [19]. Although few investigators have evaluated a broader continuum of sedentary and PA intensity outcomes, evidence is building supporting health benefits of engaging in LPA and limiting SB [20-25]. LPA has been defined as energy expenditure at the level of 1.6-2.9 metabolic equivalents (e.g., slow walking, sitting and writing, cooking, washing dishes), increases metabolic rate, and contributes to total daily energy expenditure [26]. Targeting increasing LPA as a way to decrease SB may be a unique intervention strategy in high-risk youth (minority, overweight/obese) and offers a number of potential benefits compared to targeting MVPA. LPA may be easier to increase given its higher occurrence and ability to address common barriers of MVPA such as injury, safety, cost and access concerns and feeling embarrassed of low skill levels or sweating [27-31]. Overweight/obese youth may also benefit more from targeting increases in LPA compared to healthy-weight individuals due to the relative increased energy expenditure from lighter activities [32].

Despite the health benefits and potential intervention opportunities of LPA, many studies, including national surveillance studies, do not measure LPA or sedentary behavior (SB) $[33,34]$. While studies have shown that health behaviors cluster in consistent and inconsistent ways [35], previous literature has tended to emphasize only one behavior within the SB and PA spectrums $[3,36]$. Thus, although a substantial amount of literature has investigated self-efficacy, parenting factors, and home and neighborhoods supports in MVPA, findings remain mixed $[10,35]$, and literature examining these key factors in relation to SB or LPA is lacking. Therefore, the current study expands on previous studies by investigating self-efficacy, parenting, and perceptions of social environmental factors across all activity intensities, including SB, LPA, and MVPA.

Considering multiple systems simultaneously (e.g., selfefficacy, parenting, and social environmental factors) can facilitate a broader, contextual, and more complete understanding of the multiple determinants of SB, LPA, and MVPA. However, a recent review showed studies on family and environmental correlates of SB and MVPA, specifically in underserved youth, are inconsistent and seldom investigate influences from multiple levels [28]. Thus, the purpose of the current study was to examine associations of individual (i.e., self-efficacy), social (i.e., parental support, nurturance, limit-setting, and monitoring), and environmental (perceptions of home resources and neighborhood supports for PA) factors with SB, LPA and MVPA in overweight/obese, underserved adolescents.

\section{Methods}

\section{Participants and procedure}

Participants were 201 low-income or racial/ethnic minority adolescents (10-17 years old). Inclusion criteria were BMI at or above the 85th percentile and ability to speak/ write English. Exclusion criteria included having a chronic medical condition, developmental disability, or serious psychiatric disorder. The current study targeted overweight, underserved youth in pediatric clinics serving a low-income population (75\% Medicaid patients) as this unique group of youth can be considered to be at especially high risk for negative health trajectories. Recruitment efforts included referral through clinic pediatricians, community events, and passive consent (i.e., direct mailing by pediatricians in accordance with HIPAA requirements). Participants were primarily recruited through pediatrician referrals (45\%) and passive consent (32\%). Participants recruited through pediatricians and passive consent had a significantly higher BMI compared to participants recruited in community events. No differences in SB and MVPA levels were found across recruitment methods. Of those eligible and invited to participate, $45.7 \%$ were enrolled, $22.3 \%$ declined, $23.0 \%$ did not show up for their appointment, and $9 \%$ failed to meet BMI inclusion criteria at the first appointment.

Participants took part in two appointments one week apart after completing informed consent. The first visit included consent/assent and anthropometric measures (height, weight, and waist circumference for both parent and child). Directions for wearing accelerometers were given. At the second appointment, accelerometers were collected and questionnaires were administered to participants and caregivers. Families were given educational materials, health information, and $\$ 30$ compensation for participation. Of 201 families enrolled, 98\% returned for 
the second visit. The study was approved by the institutional review board of the University of South Carolina.

\section{Measures}

\section{Self-efficacy}

The Relapse Prevention factor of a previously validated scale [37] was used in the current study to evaluate barriers for PA. The scale has demonstrated good internal consistency and validity in underserved youth [38]. Adolescents responded to 9 items on PA indicating how confident they were they could motivate themselves to change their exercise habits when facing barriers. This subscale was chosen as high-risk youth may face additional barriers to increasing PA [5]. Responses were recorded on a three-point scale (a little sure, sure, very sure). Internal consistency for the current study was high $(\alpha=.87$ for PA).

\section{Parent social support}

Adolescents completed a measure of parent social support for PA using a modified version of a previously validated scale [39]. Participants responded to 13 items indicating how often in the past month a parent has provided support (5 point scale from never to always). Items were averaged to create a social support measure. Previous research has demonstrated acceptable psychometric properties, and a subscale has been shown to be predictive of MVPA in underserved adolescents $[39,40]$. Internal consistency for the current study was high $(\alpha=.89)$.

\section{Parent limit-setting and monitoring}

Limit-setting and monitoring subscales of a previously validated scale [41] were used to assess frequency of limits on adolescents' health behaviors (ie., limiting screen time, sodas, and snacks and tracking of adolescents' eating and activity habits). Previous research supports behaviorspecific measures over general measures [42]. The scales in the current study were chosen to balance a focus on obesity-related health behaviors with participant burden from multiple behavior-specific measures. Parents reported on six questions (strongly disagree to strongly agree) for limit-setting and seven items (never to almost always) for monitoring on five-point scales. Previous literature has supported reliability, factor structure, and predictive validity in parents of minority youth [41]. Internal consistency for the current study was high ( $\alpha=.86$ for both).

\section{Parental nurturance}

The nurturance subscale of a parenting dimensions scale [18] was used to assess parental warmth and interactive style (e.g., "Family members easily express warmth and caring towards each other"). Parents responded to five items on a five-point scale (not at all to exactly like me).
Previous literature has supported the scale's factor structure, reliability, and stability over time [18]. Internal consistency for the current study was high $(\alpha=.82)$.

\section{Home resources}

Home resources for PA was parent-reported using 12 items that assessed the availability of PA equipment in the home (e.g., balls, covered areas) and has shown acceptable reliability in an underserved sample [12]. Items were summed, and internal consistency for the current study was marginal $(\alpha=.61)$.

\section{Perceived neighborhood support}

Parents completed a 16-item measure of perceived neighborhood supports (i.e., within 0.5 -mile radius or 10-minute walk) for PA used in previous work with underserved families. The scale has shown acceptable reliability and predictive validity [associated with MVPA; 12]. The scale assessed perceptions of social and physical environmental neighborhood supports for PA (e.g., sidewalks, free from unattended dogs, recreation center, waving to neighbors) using a 5-point scale (strongly disagree to strongly agree). Items were averaged, and internal consistency for the current study was moderate $(\alpha=.73)$.

\section{Physical activity}

Objective assessments of adolescents' SB, LPA, and MVPA were obtained with omni-directional accelerometers over seven consecutive days. Each day of accelerometer data was divided into five intervals: $6-9 \mathrm{am}, 9-2 \mathrm{pm}, 2-5 \mathrm{pm}$, 5-8 pm, and $8 \mathrm{pm}$ to midnight [43]. Data were recorded in 1-minute epochs [44], and 90 consecutive zero-counts were used to indicate non-wear [45]. Raw activity data were converted into time spent in SB, LPA, and MVPA based on validated Actical-specific activity count thresholds for children identified using a range of sedentary and active tasks by Puyau et al. [46] (where SB: <100, LPA: 100- <1,500; MPA: 1,500-<6,500, and VPA: $>6,500)$. After imputation (described below) intervals were summed for all time points each day and averaged across days to provide one measure of average daily minutes of SB, LPA, and MVPA, respectively.

\section{Data analytic plan}

Descriptive statistics were examined for demographic characteristics. Analyses by weight status category were not examined as only $2.8 \%$ of youth had a BMI percentile $\geq 85$ th and $<95$ th [47]. To examine social and environmental associations with $\mathrm{SB}$ and $\mathrm{PA}$, three separate multiple regression analyses (SB, LPA, MVPA) were conducted. Independent variables included self-efficacy, parental limit-setting, monitoring, nurturance, parental support, home resources, and neighborhood support. 
Sex and age were included as covariates. Variables were entered in a stepwise manner to determine the unique variance accounted for by each bioecological level (ie, covariates, individual, social, environmental). Post-hoc power simulations $(10,000$ simulations, $\mathrm{p}=.05, \mathrm{n}=201)$ confirmed the study was $79 \%$ powered to detect standardized beta effect sizes of 20 .

Participants with no accelerometer data $(n=20)$ due to lost belts, malfunctions, or less than the 4 days (with $\geq 10$ hours of wear) of valid wear time needed to obtain reliable PA estimates were excluded from analyses [48]. These participants showed no differences from included participants on any study variables. Remaining missing data were dealt with using multiple imputation (20 imputations) to provide unbiased parameter estimates and standard errors as previously proposed [43]. Multiple imputations were conducted in $\mathrm{R}$ using the MICE package and included all demographic, psychosocial, SB and PA variables. Seventy-six percent of participants had 7 days of wear, and the remaining participants had some non-compliance but at least 4 days of valid wear. Some surveys or items were missing $(\sim 5 \%)$. Fractions of missing information are reported.

\section{Results}

\section{Demographics}

Table 1 shows the demographic data for the study sample. Youth were $13.3 \pm 2.1$ years old, predominantly racial/ ethnic minorities (88\% minority including $79 \%$ African American) and had an average BMI of $33.5 \pm 7.0$ (see Table 1). Caregivers were $42.2 \pm 10.4$ years old and had average BMI of $36.9 \pm 9.9$. Approximately $59 \%$ of the sample reported income under $\$ 25,000$ USD.

\section{Correlations}

Correlations are shown in Table 2. MVPA was significantly correlated with LPA $(r=0.38)$ and SB $(r=-.34, p<.05$ for all). Increased age was significantly associated with higher SB $(r=.14)$ and lower LPA $(r=-.34)$. Higher levels of LPA were associated with higher levels of parental limit-setting $(\mathrm{r}=.16)$ and parental monitoring $(\mathrm{r}=.15, \mathrm{p}<.05$ for all $)$. SB and MVPA were not significantly associated with any of the individual, social, or environmental factors. Correlations among social factors (r's ranging from .18 - .58, $\mathrm{p}<.05$ for all) showed parental support, nurturance, limitsetting, and monitoring tended to relate to one another. Home resources and neighborhood supports were also related $(\mathrm{r}=.19, \mathrm{p}<.05)$.

\section{Self-efficacy, social and environmental supports and MVPA and LPA}

Regression analyses showed that being female was associated with significantly lower levels of MVPA (see Table 3). No other factors were significant. The overall
Table 1 Participant demographics and psychosocial characteristics $(\mathbf{n}=\mathbf{1 8 1})$

\begin{tabular}{lll}
\hline Variable & Mean & Standard deviation \\
\hline Female (count/\%) & 109 & $60 \%$ \\
Ethnicity (count/\%) & & \\
$\quad$ African American & 143 & $79 \%$ \\
$\quad$ Caucasian & 21 & $12 \%$ \\
$\quad$ Latino & 15 & $8 \%$ \\
$\quad$ Other & 2 & $1 \%$ \\
Age (yrs) & 13.3 & 2.1 \\
BMI (kg/m ${ }^{2}$ ) & 33.5 & 7.0 \\
MVPA (average min/day) & 27.6 & 21.2 \\
Light PA (average min/day) & 237.0 & 71.4 \\
Sedentary behavior (average min/day) & 749.0 & 123.0 \\
Self-efficacy for PA & 2.0 & 0.5 \\
Parental nurturance & 4.7 & 0.9 \\
Parental support & 2.6 & 1.1 \\
Parental limit-setting & 3.8 & 1.0 \\
Parental monitoring & 3.5 & 0.9 \\
Home resources & 5.4 & 2.4 \\
Neighborhood support & 2.7 & 0.5
\end{tabular}

Note: Values reported using a single imputation and shown as Mean (SD) or Count (\%). Self-efficacy was reported using a 3-point scale. Parenting and neighborhood variables were reported using 5 -point scales. Home resources were summed and ranged from $0-12$. For all scales, higher scores indicated more of the construct. Environmental measures were parent-reported perceptions of home resources and neighborhood supports.

model accounted for 9\% of the variance in MVPA. Covariates accounted for $7 \%$ of the variance $(F(2,178)=$ $6.75, \mathrm{p}<.05)$, the individual level predictor (self-efficacy) accounted for an additional $0.4 \%(F(3,177)=4.72$, $\mathrm{p}<.05$ ), family level predictors (parent support, tracking, limit-setting, nurturance) accounted for an additional 1.2\% $(\mathrm{F}(7,173)=2.27,<.05)$, and environmental level predictors (home resources, neighborhood support) accounted for an additional $0.8 \%(\mathrm{~F}(9,171)=1.97, \mathrm{p}<.05)$.

Regression analyses showed that older age was significantly associated with less LPA, and parent social support and neighborhood support were significantly positively associated with LPA (see Table 3 ). The overall model accounted for $22 \%$ of the variance in LPA. Covariates accounted for $14.3 \%$ of the variance $(F(2,178)=$ $14.9, \mathrm{p}<.05$ ), the individual level predictor (self-efficacy) accounted for an additional $0.1 \%(\mathrm{~F}(4,196)=2.64$, $\mathrm{p}<.05$ ), family level predictors (parent support, tracking, limit-setting, nurturance) accounted for an additional 4.5\% $(F(7,173)=5.77, \mathrm{p}<.05)$, and environmental level predictors (home resources, neighborhood support) accounted for an additional $2.7 \%(\mathrm{~F}(9,171)=5.23, \mathrm{p}<.05)$. 
Table 2 Correlations among individual, social, and environmental determinants and sedentary behavior and physical activity

\begin{tabular}{|c|c|c|c|c|c|c|c|c|c|c|c|}
\hline & Age & BMI & MVPA & LPA & SB & SE & PS & $\mathrm{N}$ & LS & $M$ & HR \\
\hline$\overline{\mathrm{BMI}}$ & $0.27^{*}$ & & & & & & & & & & \\
\hline MVPA & -0.13 & -0.09 & & & & & & & & & \\
\hline LPA & $-0.34^{*}$ & -0.11 & $0.38^{*}$ & & & & & & & & \\
\hline SB & $0.14^{*}$ & 0.02 & $-0.34^{*}$ & -0.08 & & & & & & & \\
\hline Self efficacy & -0.04 & -0.07 & 0.06 & 0.04 & -0.12 & & & & & & \\
\hline Parental support & -0.07 & $0.15^{*}$ & 0.09 & $0.18^{*}$ & -0.12 & $0.34^{*}$ & & & & & \\
\hline Nurturance & -0.11 & 0.04 & 0.11 & 0.01 & -0.02 & 0.09 & $0.25^{*}$ & & & & \\
\hline Limit-setting & $-0.29^{*}$ & -0.08 & 0.11 & $0.16^{*}$ & -0.04 & 0.07 & $0.24^{*}$ & $0.24^{*}$ & & & \\
\hline Monitoring & $-0.21^{*}$ & 0.03 & 0.07 & $0.15^{*}$ & 0.04 & 0.11 & $0.18^{*}$ & $0.30^{*}$ & $0.58^{*}$ & & \\
\hline Home resources & -0.15 & -0.12 & 0.09 & -0.01 & 0.10 & -0.11 & 0.09 & 0.11 & 0.14 & 0.10 & \\
\hline Neighborhood supports & 0.01 & 0.03 & 0.08 & 0.13 & 0.00 & 0.03 & 0.04 & $0.16^{*}$ & -0.01 & -0.01 & $0.19^{*}$ \\
\hline
\end{tabular}

${ }^{*}=p<.05$. MVPA = moderate-to-vigorous physical activity, LPA = light physical activity, SB = sedentary behavior.

Notes: Column headings correspond to row names. Environmental measures were parent-reported perceptions of home resources and neighborhood supports.

Table 3 Regression analyses predicting adolescents' moderate-to-vigorous physical activity and light physical activity $(n=181)$

\begin{tabular}{|c|c|c|c|c|c|c|c|c|}
\hline & Est & SE & $\beta$ & $p$ & Lower $\mathrm{Cl}$ & Upper Cl & FMI & $\Delta \mathrm{R}^{2}$ \\
\hline \multicolumn{9}{|c|}{ MVPA: $\left(F(9,171)=1.97, R^{2=} .09\right)$} \\
\hline (Intercept) & 19.22 & 18.56 & 0.00 & 0.30 & -17.16 & 55.60 & 0.06 & Covariates $=.07$ \\
\hline Female & -9.04 & 3.22 & -0.21 & $<0.01$ & -15.34 & -2.74 & 0.03 & \\
\hline Age & -0.76 & 0.80 & -0.08 & 0.34 & -2.33 & 0.80 & 0.06 & \\
\hline Self-efficacy & 1.44 & 3.25 & 0.04 & 0.66 & -4.93 & 7.80 & 0.05 & Individual = .004 \\
\hline Parent support & 0.82 & 1.85 & 0.04 & 0.66 & -2.81 & 4.46 & 0.06 & Social $=.012$ \\
\hline Nurturance & 0.44 & 1.85 & 0.02 & 0.81 & -3.19 & 4.07 & 0.08 & \\
\hline Limit-setting & 0.99 & 2.00 & 0.05 & 0.62 & -2.93 & 4.91 & 0.06 & \\
\hline Monitoring & 0.90 & 2.33 & 0.04 & 0.70 & -3.67 & 5.47 & 0.10 & \\
\hline Home resources & 0.13 & 0.67 & 0.01 & 0.85 & -1.19 & 1.45 & 0.05 & Environmental $=.008$ \\
\hline Neighborhood support & 3.47 & 3.16 & 0.09 & 0.27 & -2.71 & 9.66 & 0.04 & \\
\hline \multicolumn{9}{|c|}{ Light PA: $\left(F(9,171)=5.23, R^{2=} .22\right)$} \\
\hline (Intercept) & 350.23 & 58.42 & 0.00 & $<0.01$ & 235.71 & 464.75 & 0.04 & Covariates $=.143$ \\
\hline Female & -17.39 & 10.48 & -0.12 & 0.10 & -37.95 & 3.16 & 0.07 & \\
\hline Age & -11.33 & 2.51 & -0.33 & $<0.01$ & -16.25 & -6.40 & 0.03 & \\
\hline Self-efficacy & -9.47 & 10.31 & -0.07 & 0.36 & -29.69 & 10.74 & 0.04 & Individual = .001 \\
\hline Parent support & 15.67 & 5.88 & 0.21 & 0.01 & 4.14 & 27.21 & 0.05 & Social $=.045$ \\
\hline Nurturance & -8.66 & 5.85 & -0.11 & 0.14 & -20.13 & 2.81 & 0.06 & \\
\hline Limit-setting & 2.30 & 6.36 & 0.03 & 0.72 & -10.17 & 14.77 & 0.06 & \\
\hline Monitoring & 7.24 & 7.36 & 0.09 & 0.33 & -7.19 & 21.66 & 0.08 & \\
\hline Home resources & -3.47 & 2.14 & -0.12 & 0.10 & -7.66 & 0.71 & 0.04 & Environmental $=.027$ \\
\hline Neighborhood support & 19.97 & 10.15 & 0.14 & 0.049 & 0.08 & 39.87 & 0.06 & \\
\hline
\end{tabular}

Est $=$ Estimate, $\mathrm{SE}=$ standard error,$\beta=$ standardized beta, $\mathrm{Cl}=$ confidence interval, $\mathrm{FMI}=$ fraction of missing information

Note: environmental measures were parent-reported perceptions of home resources and neighborhood supports. 
Self-efficacy, social and environmental supports and SB Regression analyses showed that increased age displayed a trend with increased levels of SB (see Table 4). No other factors were significant. The overall model accounted for $7.7 \%$ of the variance in SB. Covariates accounted for $2.9 \%$ of the variance $(\mathrm{F}(2,178)=2.66, \mathrm{p}>.05)$, the individual level predictor (self-efficacy) accounted for an additional $1.4 \%(\mathrm{~F}(3,177)=2.66, \mathrm{p}<.05)$, family level predictors (parent support, tracking, limit-setting, nurturance) accounted for an additional $1.7 \%(F(7,173)=1.57,>.05)$, and environmental level predictors (home resources, neighborhood support) accounted for an additional $1.7 \%(\mathrm{~F}(9,171)=1.59$, $\mathrm{p}>.05)$.

\section{Discussion}

The current study simultaneously examined key individual, social and perceived environmental predictors of accelerometer measured SB, LPA and MVPA in youth who were at high-risk for later chronic health diseases. Results of the current study showed parent social support and perceived neighborhood support (including safety, access, aesthetics, and social cohesion) were significantly positively associated with LPA. However, no significant associations with SB or MVPA were observed.

Results from the current study are among the first to demonstrate that parental social support and perceived neighborhood support (including safety, access, aesthetics, and social cohesion) are significantly associated with accelerometer-measured LPA in overweight/obese youth. In addition, family and environmental levels accounted for more variance in MVPA and LPA than the individual level. In line with the dual-process view of direct environmental influences, this may indicate that parental and neighborhood supports cue some automatic and habitual processes that regulate LPA [1]. Previous literature investigating individual and environmental factors has explored the role of environmental access in facilitating intentions and personality factors for MVPA $[7,8]$. The current study expands on previous work through the inclusion of parenting factors, which may be particularly important for high-risk youth. While previous studies examining parenting variables for youth's MVPA have shown inconsistent findings [49], the current study expands on past work by showing that both parental and perceived social environmental supports are associated with higher levels of LPA but not SB or MVPA in overweight/obese youth.

Given the growing evidence supporting the health benefits of LPA $[3,26]$, results of the current study support the need for additional research into the key determinants of LPA so that effective interventions targeting LPA may be developed. Previous interventions have utilized strategies, such as promoting dance or other extracurricular physical activities, to simultaneously increase MVPA and decrease SB [50,51] and have also focused on targeting higher intensity PA [52]. Results of the current study may compliment previous intervention strategies $[51,53]$ through helping parents to build support for lower intensity PA in youth and to think creatively about how their neighborhood environment may be used for increasing LPA. For example, interventionists may consider noting the more enjoyable qualities of engaging in LPA for overweight/obese youth that relate to standing and light activities.

In the current study underserved adolescents showed particularly high levels of SB and particularly low levels of LPA and MVPA. Other samples of African American youth have found comparable MVPA levels [27,34,54] but higher levels of LPA $[27,55]$ compared to the current study sample. In addition, the current study found MVPA was significantly positively associated with LPA and negatively associated with SB. Previous research has shown mixed findings with some showing a positive relation with SB

Table 4 Regression analyses predicting adolescents' sedentary behavior $(n=181)$

\begin{tabular}{|c|c|c|c|c|c|c|c|c|}
\hline & Est & SE & $\beta$ & $p$ & Lower $\mathrm{Cl}$ & Upper Cl & FMI & $\Delta \mathrm{R}^{2}$ \\
\hline \multicolumn{9}{|c|}{ Sedentary Behavior: $\left(F(9,171)=1.59, R^{2=} .08\right)$} \\
\hline (Intercept) & 621.30 & 107.25 & 0.00 & 0.00 & 411.09 & 831.52 & 0.00 & Covariates $=.029$ \\
\hline Female & 26.43 & 18.95 & 0.11 & 0.16 & -10.72 & 63.58 & 0.00 & \\
\hline Age & 8.58 & 4.61 & 0.15 & 0.06 & -0.46 & 17.62 & 0.00 & \\
\hline Self-efficacy & -17.92 & 18.99 & -0.07 & 0.35 & -55.13 & 19.30 & 0.01 & Individual $=.014$ \\
\hline Parent support & -13.48 & 10.78 & -0.10 & 0.21 & -34.61 & 7.66 & 0.01 & Social $=.017$ \\
\hline Nurturance & 1.72 & 10.67 & 0.01 & 0.87 & -19.20 & 22.64 & 0.01 & \\
\hline Limit-setting & -6.23 & 11.57 & -0.05 & 0.59 & -28.90 & 16.44 & 0.00 & \\
\hline Monitoring & 16.59 & 13.24 & 0.12 & 0.21 & -9.36 & 42.54 & 0.00 & \\
\hline Home resources & 7.01 & 3.92 & 0.14 & 0.07 & -0.69 & 14.70 & 0.00 & Environmental $=.017$ \\
\hline Neighborhood support & -5.77 & 18.47 & -0.02 & 0.76 & -41.97 & 30.43 & 0.00 & \\
\hline
\end{tabular}

Est $=$ Estimate, $\mathrm{SE}=$ standard error, $\beta=$ standardized beta, $\mathrm{Cl}=$ confidence interval, $\mathrm{FMI}=$ fraction of missing information Note: environmental measures were parent-reported perceptions of home resources and neighborhood supports. 
and MVPA and others showing a negative relation [35]. In line with the current study's findings, longitudinal studies with underserved youth have also shown LPA is displaced by sedentary behavior as children age $[55,56]$. LPA may be important to target because it occurs more frequently and could be more easily modified in this high-risk group. LPA may offer benefits particularly important for highrisk youth who may have more common barriers to MVPA [27-31]. High-risk youth may also benefit from relative increases in energy expenditure from lighter activities compared to healthy-weight youth [32] and may not find LPA to have as great a decrease in reinforcing value compared to MVPA [57]. As such, parental factors and perceptions of social environmental influences on LPA may be distinct from MVPA. Future research should measure independent and joint contributions of key influences across SB, LPA and MVPA to identify the most effective strategies to target behaviors that cluster in healthy ways [35].

The current study also did not show any significant associations with SB or MVPA. Although this was surprising, these findings are similar to others that have demonstrated null or mixed associations between PA and self-efficacy [10], parental support [9], and perceived and actual neighborhood supports [10], even in underserved youth [28]. Similarly, mixed associations have been found for correlates of $\mathrm{SB}$, though they overwhelmingly focus on the specific SB of television viewing [36]. Overall, these studies and the current study indicate that there are a number of complex bioecological influences and that isolated factors can be expected to have modest effects [10]. In the current study it may be that for overweight, underserved youth, parental and neighborhood supports are directly associated with LPA. In contrast, potential moderators or mechanisms of key bioecological factors for MVPA and SB may need to be explored in this unique, high-risk population, such as those proposed by the dual-process model [1]. Future research should target parenting strategies (e.g., autonomy support, norms, attitudes, access), in interventions to increase PA in high-risk youth [53].

There are several limitations with the present study. This study utilized a relatively small sample from a specific demographic of low-income, overweight, minority youth, which limits the generalizability of the findings. The current study used a cross-sectional design and thus cannot be used to draw causal conclusions. Furthermore, measures were not obtained specific to SB versus LPA versus MVPA. In addition, the current study was not powered to examine interactions across bioecological levels or dual-process influences on SB and PA. Future investigations of moderation and mediation employing longitudinal designs and larger samples sizes are needed to better understand how to target interventions for youth who are overweight. For example, dual-processes models propose that cognitive factors will mediate the role of the environment on behavioral outcomes of $\mathrm{SB}$, LPA, and MVPA [1]. However, the study has important strengths including a unique, high-risk sample of underserved youth, the use of accelerometer estimates of SB and PA, and the simultaneous examination of multiple ecological predictors across the full range of SB and PA intensities.

\section{Conclusions}

Overall, results from the current study emphasize the importance of family level and neighborhood level factors on understanding LPA in overweight underserved youth. Specifically, parent support and perceived neighborhood support were associated with higher levels of LPA in highrisk youth but not with SB or MVPA. Future studies should also explore interactions and mediation effects of cognitive and environmental factors of LPA, particularly for high-risk, underserved youth. These results have important implications that suggest that health promotion efforts should target social and environmental supports for increasing LPA in youth who are overweight/obese.

\section{Abbreviations}

SB: Sedentary behavior; PA: Physical activity; LPA: Light physical activity; MVPA: Moderate-to-vigorous physical activity.

\section{Competing interest}

The authors declare they have no competing interests.

\section{Authors' contributions}

HGL participated in obtaining funding, study design, collecting and analyzing data, and took responsibility for drafting the manuscript. DKW participated in obtaining funding, study design, and edited and approved the manuscript. Both authors read and approved the final manuscript.

\section{Acknowledgements}

This article was supported by three grants funded by the National Institutes of Health: F31 DK086358 to HGL and DKW, R01 HD072153 to DKW, and F32 DK100248. The authors wish to acknowledge Lee Van Horn, PhD, Angela Liese, PhD, and Nicole Zarrett, PhD for their contributions to the study conceptualization and design and Kimberly Hightower, MD and Lynn Wilson, MD for their invaluable role in recruiting participants. The also authors wish to acknowledge the many research assistants and research assistant leaders including Ann Newsom, Melissa Laitner, and Patricia Hitt for their help in data collection and data entry.

\section{Author details}

${ }^{1}$ Center for Obesity Research and Education, Temple University, $3223 \mathrm{~N}$. Broad Street suite 175, Philadelphia, PA 19140, USA. ²Department of Psychology, University of South Carolina, Columbia, SC, USA.

Received: 11 December 2013 Accepted: 2 July 2014

\section{References}

1. Kremers S, De Bruijn G, Visscher TLS, Van Mechelen W, De Vries NK, Brug J: Environmental influences on energy balance-related behaviors: a dual-process view. Int J Behav Nutr Phys Act 2006, 3(9).

2. Sallis JF: Measuring Environmental and Policy Exposures: Which Ones? In Institute of Medicine Panel on Accelerating Progress in Childhood Obesity Prevention. Irvine, CA: 2011. Accessed on 7/7/14 from: http://www.iom.edu/ Global/Meetings.aspx. 
3. Powell KE, Paluch AE, Blair SN: Physical activity for health: What kind? How much? How intense? On top of what? Annu Rev Public Health 2011, 32:349-365.

4. Goran MI, Ball GDC, Cruz ML: Obesity and risk of type 2 diabetes and cardiovascular disease in children and adolescents. $J$ Clin Endocrinol Metab 2003, 88(4):1417-1427

5. Wilson DK: New perspectives on health disparities and obesity interventions in youth. J Pediatr Psychol 2009, 34(3):231-244.

6. Bronfenbrenner U: The Ecology of Human Development: Experiments by Nature and Design. Cambridge, MA: Harvard University Press; 1979.

7. Rhodes RE, Courneya KS, Blanchard CM, Plotnikoff RC: Prediction of leisuretime walking: an integration of social cognitive, perceived environmental, and personality factors. Int J Behav Nutr Phys Act 2007, 4(51).

8. Prins R, Van Empelen P, Te Velde S, Timperio A, Van Lenthe F, Tak N, Crawford D, Brug J, Oenema A: Availability of sports facilities as moderator of the intention-sports participation relationship among adolescents. Health Educ Res 2010, 25(3):489-497.

9. Van Der Horst K, Paw MJCA, Twisk JWR, Van Mechelen W: A brief review on correlates of physical activity and sedentariness in youth. Med Sci Sports Exerc 2007, 39(8):1241-1250

10. Biddle SJH, Atkin AJ, Cavill N, Foster C: Correlates of physical activity in youth: a review of quantitative systematic reviews. Int Rev Sport Exerc Psychol 2011, 4(1):25-49.

11. Peterson MS, Lawman HG, Wilson DK, Fairchild A, Van Horn ML: The association of self-efficacy and parent social support on physical activity in male and female adolescents. Health Psychol 2013, 32(6):666-674.

12. Wilson DK, Lawman HG, Segal M, Chappell S: Neighborhood and parental supports for physical activity in minority adolescents. Am J Prev Med 2011, 41(4):399-406

13. van der Horst K, Oenema A, Ferreira I, Wendel-Vos W, Giskes K, Van Lenthe F, Brug J: A systematic review of environmental correlates of obesityrelated dietary behaviors in youth. Health Educ Res 2007, 22(2):203-226.

14. Davison KK, Jago R: Change in parent and peer support across ages 9 to $15 \mathrm{yr}$ and adolescent Girls' physical activity. Med Sci Sports Exerc 2009, 41(9):1816-1825.

15. Hennessy E, Hughes SO, Goldberg J, Hyatt R, Economos C: Parent-child interactions and objectively measured child physical activity: a crosssectional study. Int J Behav Nutr Phys Act 2010, 7:71.

16. Schneider E, Wilson DK, Kitzman-Ulrich H, St George SM, Alia KA: Associations of parenting factors with adolescent body mass index in an underserved population. J Obesity 2013, 2013(715618):7.

17. Alia KA, Wilson DK, St George SM, Schneider E, Kitzman-Ulrich H: Effects of parenting style and parent-related weight and diet on adolescent weight status. J Pediatr Psychol 2013, 38(3):321-329.

18. Olvera N, Power TG: Brief report: parenting styles and obesity in Mexican American children: a longitudinal study. J Pediatr Psychol 2010, 35(3):243-249.

19. Anderson CB, Hughes SO, Fuemmeler BF: Parent-child attitude congruence on type and intensity of physical activity: testing multiple mediators of sedentary behavior in older children. Health Psychol 2009 28(4):428-438

20. Cliff D, Okely AD, Burrows T, Jones R, Morgan PJ, Collins CE, Baur LA Objectively measured sedentary behavior, physical activity, and plasma lipids in overweight and obese children. Obesity 2013, 21(2):382-385.

21. Wong ND, Hei TK, Qayundah PY, Davidson DM, Bassin SL, Gold KV: Television viewing and pediatric hypercholesterolemia. Pediatrics 1992, 90(1):75-79.

22. Ekelund U, Brage S, Froberg K, Harro M, Anderssen S, Sardinha LB, Riddoch C, Andersen LB: TV viewing and physical activity are independently associated with metabolic risk in children: The European Youth Heart Study. PLoS Med 2006, 3(12):2449-2456.

23. Martinez-Gomez D, Tucker J, Heelan KA, Welk GJ, Eisenmann JC: Associations between sedentary behavior and blood pressure in young children. Arch Pediatr Adolesc Med 2009, 163(8):724-730.

24. Pearson N, Biddle S: Sedentary behavior and dietary intake in children adolescents, and adults: a systematic review. Am J Prev Med 2011, 41(2):178-188

25. Must A, Tybor DJ: Physical activity and sedentary behavior: a review of longitudinal studies of weight and adiposity in youth. Int J Obes 2005, 29:S84-S96.

26. Pate $R$, O'Neill JR, Lobelo F: The evolving definition of "sedentary". Exerc Sport Sci Rev 2008, 36(4):173-178.
27. Trost SG, McCoy T, Vander Veur SS, Mallya G, Duffy M, Foster GD: Physical activity patterns of inner-city elementary school children. Med Sci Sports Exerc 2013, 45(3):470-474.

28. Lawman $\mathrm{HG}$, Wilson DK: A review of family and environmental correlates of health behaviors in high-risk youth. Obesity 2012, 20(6):1142-1157.

29. Wilson DK, Kirtland KA, Ainsworth BE, Addy CL: Socioeconomic status and perceptions of access and safety for physical activity. Ann Behav Med 2004, 28(1):20-28.

30. Dwyer J, Allison K, Goldenberg E, Fein A, Yoshida K, Boutilier M: Adolescent girls' perceived barriers to participation in physical activity. Adolescence 2006, 41(161):75-89.

31. Grieser M, Vu M, Bedimo-Rung A, Neumark-Sztainer D, Moody J, Young D, Moe S: Physical activity attitudes, preferences, and practices in African American, Hispanic, and Caucasian girls. Health Educ Behav 2006, 33(1):40-51.

32. Ekelund U, Aman J, Yngve A, Renman C, Westerterp K, Sjostrom M: Physical activity but not energy expenditure is reduced in obese adolescents: a case-control study. Am J Clin Nutr 2002, 76(5):935-941.

33. Mota J, Esculcas C: Leisure-time physical activity behavior: Structured and unstructured choices according to sex, age, and level of physical activity. Int J Behav Med 2002, 9(2):111-121.

34. Troiano RP, Berrigan D, Dodd KW, Masse LC, Tilert T, McDowell M: Physical activity in the united states measured by accelerometer. Med Sci Sports Exerc 2008, 40(1):181-188

35. Leech R, McNaughton S, Timperio A: The clustering of diet, physical activity and sedentary behavior in children and adolescents: a review. Int J Behav Nutr Phys Act 2014, 11(4).

36. Salmon J, Tremblay M, Marshall SJ, Hume C: Health risks, correlates, and interventions to reduce sedentary behavior in young people. Am J Prev Med 2011, 41(2):197-206.

37. Sallis JF, Pinski RB, Grossman RM, Patterson TL: The development of selfefficacy scales for health-related diet and exercise behaviors. Health Educ Res 1988, 3(3):283-292

38. Wilson DK, Evans AE, Williams J, Mixon G, Sirard JR, Pate R: A preliminary test of a student-centered intervention on increasing physical activity in underserved adolescents. Ann Behav Med 2005, 30(2):119-124.

39. Sallis JF, Grossman RM, Pinski RB, Patterson TL, Nader PR: The development of scales to measure social support for diet and exercise behaviors. Prev Med 1987, 16(6):825-836.

40. Kitzman-Ulrich H, Wilson DK, Van Horn ML, Lawman HG: Relationship of body mass index and psychosocial factors on physical activity in underserved adolescent boys and girls. Health Psychol 2010, 29(5):506-513.

41. Larios SE, Ayala GX, Arredondo EM, Baquero B, Elder JP: Development and validation of a scale to measure Latino parenting strategies related to children's obesigenic behaviors. The parenting strategies for eating and activity scale (PEAS). Appetite 2009, 52(1):166-172.

42. Glanz K, Rimer BK, Lewis FM: Health Behavior and Health Education: Theory, Research, and Practice. 3rd edition. San Fransisco, CA: Jossey-Bass; 2002

43. Catellier DJ, Hannan PJ, Murray DM, Addy CL, Conway TL, Song Y, Rice JC: Imputation of missing data when measuring physical activity by accelerometry. Med Sci Sports Exerc 2005, 37:S555-S562.

44. Welk GJ, Schaben JA, Morrow JR Jr: Reliability of accelerometry-based activity monitors: a generalizability study. Med Sci Sports Exerc 2004, 36(9):1637-1645.

45. Choi L, Liu Z, Matthews CE, Buchowski MS: Validation of accelerometer wear and nonwear time classification algorithm. Med Sci Sports Exerc 2011, 43(2):357-364

46. Puyau MR, Adolph AL, Vohra FA, Zakeri I, Butte NF: Prediction of activity energy expenditure using accelerometers in children. Med Sci Sports Exerc 2004, 36(9):1625-1631.

47. Kuczmarski RJ, Ogden CL, Guo SS, Grummer-Strawn LM, Flegal KM, Mei Z, Curtin LR, Roche AF, Johnson CL: 2000 CDC growth charts for the United States: methods and development. Vital Health Stat 11 2002, 246(246):1-190.

48. Rowlands AV: Accelerometer assessment of physical activity in children: an update. Pediatr Exerc Sci 2007, 19(3):252-266.

49. Beets MW, Cardinal BJ, Alderman B: Parental social support and the physical activity-related behaviors of youth: a review. Health Educ Behav 2010, 37:621-645.

50. DeMattia L, Lemont $L$, Meurer L: Do interventions to limit sedentary behaviors change behavior and reduce childhood obesity? A critical review of the literature. Obes Rev 2007, 8(1):69-81. 
51. Steeves J, Thompson D, Bassett D, Fitzhugh E, Raynor H: A review of different behavior modification strategies designed to reduce sedentary screen behaviors in children. J Obesity 2012, 2012:1-16.

52. Van Sluijs EM, McMinn AM, Griffin S: Effectiveness of interventions to promote physical activity in children and adolescents: systematic review of controlled trials. BMJ 2007, 355(7622):703.

53. Kitzman-Ulrich H, Wilson DK, St George SM, Lawman HG, Segal M, Fairchild AJ: The integration of a family systems approach for understanding youth obesity, physical activity, and dietary programs. Clin Child Fam Psychol Rev 2010, 13:231-253.

54. Wilson DK, Van Horn ML, Kitzman-Ulrich $H$, Saunders R, Pate R, Lawman HG, Hutto B, Griffin S, Zarrett N, Addy CL, Mansard L, Mixon G, Brown P: Results of the "Active by Choice Today" (ACT) randomized trial for increasing physical activity in low income and minority adolescents. Health Psychol 2011, 30(4):463-471.

55. Treuth MS, Baggett CD, Pratt CA, Going SB, Elder JP, Charneco EY, Webber LS: A longitudinal study of sedentary behavior and overweight in adolescent girls. Obesity 2009, 17(5):1003-1008.

56. Mitchell JA, Pate RR, Beets MW, Nader PR: Time spent in sedentary behavior and changes in childhood BMI: a longitudinal study from ages 9 to 15 years. Int J Obes 2013, 37(1):54-60.

57. Epstein L, Smith J, Vara L, Rodefer J: Behavioral economic analysis of activity choice in obese children. Health Psychol 1991, 10(5):311-316.

doi:10.1186/s12966-014-0092-1

Cite this article as: Lawman and Wilson: Associations of social and environmental supports with sedentary behavior, light and moderate-to-vigorous physical activity in obese underserved adolescents. International Journal of Behavioral Nutrition and Physical Activity 2014 11:92.

\section{Submit your next manuscript to BioMed Central and take full advantage of:}

- Convenient online submission

- Thorough peer review

- No space constraints or color figure charges

- Immediate publication on acceptance

- Inclusion in PubMed, CAS, Scopus and Google Scholar

- Research which is freely available for redistribution 